Special Issue on

Public Enterprise Performance Benchmarking

Public Enterprise

Volume 22, Issue 1, pp. 92-117, 2016

https://doi.org/pehyj.2016.2201.06

\title{
Application of Performance Evaluation System and Benchmarking to Improve Operational Efficiency of Public Enterprises
}

\author{
Istaqbal Mehdi \\ Al-Aman Holding (Pvt) Ltd, Islamabad, Pakistan \\ Received September 2015; Revised January 2016; Accepted February 2016
}

\begin{abstract}
Absence of an appropriate performance evaluation system is frequently the major cause of inefficiencies in public enterprises (PEs). Such a system is needed in PE sector largely owing to their multiple objectives which create vagueness about their goals. An evaluation system, which is based on clear and quantifiable targets linked with an incentive system, minimizes vagueness and; motivates managers to achieve specified performance level. In order to improve PEs performance in Pakistan, the "Signaling System for Public Enterprises" was set up in 1980s. The system had two major components: performance evaluation system, and incentive system which operated within the framework of an autonomy structure. Under this arrangement, managers were free to act to achieve targets and they were rewarded for good performance. The system was based on productivity linked with profitability targets. It generated positive results from the beginning. However, operations were further strengthened by improved target setting by application of benchmarking, and; by introducing the concept of strategic planning to enhance performance in short as well as long term. Supplementing the operations of signaling system with improvisations improved its effectiveness resulting in: (a) improvement in PEs profitability within four years; (b) managers acknowledged that it was a useful initiative which generated positive results; and (c) experts from the World Bank and Boston University concluded that the system motivated managers to attain targets, which improved operational efficiency of PEs.
\end{abstract}

Keywords: Benchmarking, public enterprises, performance evaluation

Reference to this paper should be made as follows: Mehdi, I. (2016). Application of Performance Evaluation System and Benchmarking to Improve Operational Efficiency of Public Enterprises. Public Enterprise, 22(1), 92-117.

DOI: 10.21571/pehyj.2016.2201.06 
I. Mehdi (2016)

Public Enterprise

Volume 22, Issue 1, pp. 92-117, 2016

https://doi.org/pehyj.2016.2201.06
International Center for

Promotion of Enterprises

\section{Introduction}

Global experience demonstrates that absence of appropriate performance evaluation of Public Enterprises (PEs) is one of the major causes of their inefficiencies. PE managers frequently lack the directions they are expected to primarily adopt because PEs have multiple objectives, such as the maximization of profit along with responsibilities like creations of employment opportunities, etc. In addition, these enterprises have plural principals, i.e., various organs of the government have different perceptions about the objectives of these enterprises. Therefore, the establishment of a target-based performance evaluation system, which is linked with incentives, is a pre-requisite for improving performance of public enterprises.

Due to multiplicity of objectives, the performance evaluation of PEs is a complex exercise. It is challenging and, at the same time critical, for stakeholders in the government to establish clear objectives of PE managers and evaluate them accordingly. Laying down clear directions for PE managers in the form of performance targets is even more difficult when a PE is operating in monopoly and/or noncompetitive environment. Such enterprises do not have matching enterprise to compare with. The operational framework of its analogue is so distinct and different that they cannot be compared with. Therefore, they cannot be taken as a standard to compare.

The following paras comprise of a discussion on various experiences and options for establishing performance targets and then evaluating them. The discussion is corroborated by a case study of establishing a target based performance evaluation system in Pakistan.

\section{Paramount Issues of PEs Performance Evaluation System}

In order to set up a performance evaluation system to improve operational efficiency of PE sector three primary questions need to be answered (Jones, 1981):

1. What is the structure of autonomy in which PE managers will operate?

2. What will be the primary objectives of PEs, i.e., what will be their criterion of evaluation?

3. What are PE managers expected to accomplish, i.e., what will the criterion value be?

\section{Autonomy Structure}

The development of an efficient autonomy structure for PE managers is one of the most fundamental issues to be addressed by the owners/stakeholders in the government. A well thought out autonomy framework is important for enterprise managers. Poor autonomy structure, where there is an over-centralization of decision-making and where there is little delegation of powers to managers, leaves little room and flexibility to move and work. It also provides an alibi to managers to hide their inefficiencies. At the same time, the owners and stakeholders in the government have to be clear about the manager's desired direction. They should provide the managers with the appropriate guidelines and directions and hold them accountable for their efforts and accomplishments. Indeed, this requires competence and skill among the controllers in the government to be able to give appropriate guidelines to managers. To develop such an efficient autonomy structure where the managers are granted required autonomy and at the same time they are held responsible for their achievements, is an extremely challenging task. One solution can be to treat public enterprise sector like a multinational corporation as a special case of the multidivisional firm. This recommended solution can be tested on a public industrial sector in Pakistan which was administrated by the 
Ministry of Production in 1980s and 1990s. The ministry controlled more than fifty operating enterprises with the assistances of eight holding corporations. The ministry was functioning as the head office, the sector corporations as regional or product-line divisions, and the companies were working as operating units. In such organizations, what classes of decisions ought to be made at the center and which at the periphery? More generally, what decisions should be made by any superior unit in a hierarchy? The answers to these questions were provided by Olivier Williamson (1975) for the multi-divisional firm and by Elliot Jacques (1976) for general hierarchies were similar and may be paraphrased as follows. The head office (or superior unit) should:

- $\quad$ Set objectives,

- Appoint the chief executive officers,

- Evaluate the performance according to those objectives,

- Reward and penalize the chief executive officers according to their evaluation,

- $\quad$ Provide resources (finance),

- Conduct long-range planning and coordination among units, and

- $\quad$ Do (almost) nothing else.

There are, thus, six narrow prescriptions and one broad proscription. The proscription is particularly important since it is so often violated. To the extent that it is violated, it is no longer possible to hold managers accountable for performance according to the objectives. The advantages of hierarchical specialization then break down (Jones, 1981).

\section{Criterion of Evaluation}

The criterion of evaluation in a way is indicating what kind of performance is expected from managers. One of the most critical questions is what criterion should be applied to evaluate managers' real performance. There was a long drawn debate on the choice of criterion. Typically, two classes of criteria are used for evaluation: Partial indicators, which demonstrate performance indicators such as labor to production or raw material to production etc. But these indicators have limitations, as only one cost is related to the total benefits. What happens to other costs is not addressed. If there is more than one partial indicator, then one benefit is counted more than once.

The other indicator is standard profit. Here, one benefit and one cost are counted only once. The problem in this is the accounting distortions and where the prices are determined by the governments which in turn influence profitability.

Profitability, in general, is the most acceptable criterion provided accounting and other distortions are removed. This was done by adjusting the standard profitability and evolving the concept of public profitability which reflect the true economic surplus generated by a PE. A short account of this concept is as follows:

\section{Public Profitability}

According to this concept for evaluating real performance of public enterprises, their efficiency is assessed by an adjusted profit. This not only takes care of the public ownership aspect of an enterprise but, also makes alternations in the normal accounting procedure which distort information concerning the real surplus generated by a public enterprise. The adjusted profit is called public profit (Jones, 1981). The concept of public profit recognizes the fact 
that while a private manager is taking care of only one economic factor (private shareholder), the manager of a public enterprise has to keep in view the interest of all the domestic economic groups. Public profit is derived from a single period variable social benefits less variable social costs; that is, the value to society of the difference between what the enterprise takes out of the economy (costs) and what it puts back (benefits) in any one period. Public profit, therefore, is:

$\mathrm{II}^{*}=\mathrm{X}-\mathrm{II}-\mathrm{R} \mathrm{k}^{\mathrm{w}}$

where:

$\mathrm{II}^{*}=$ Public Profit

$\mathrm{X}=$ Output at factor cost

II = Intermediate inputs at purchaser's prices

$\mathrm{R}=$ Factor rental expenses

$\mathrm{Rk}^{\mathrm{w}}=$ Opportunity cost of working capital

In relation to standard private profit, public profit is worked out in following manners:

Profit after taxes

+ Taxes

+ Depreciation

+ Non -operating Income

- Opportunity cost of working capital

$=$ Public Profit

Given the fixed capital at his disposal, the manager is to maximize the public profit. Thus, public profitability can be defined as follows:

Public Profitability $=\underline{\text { Variable Benefits Less Variable Costs }}$ Fixed Operating Assets

To eliminate the distortions created by government fixed prices, public profitability at constant prices is considered the appropriate criterion for assessing real performance of managers.

The greatest problem in the application of public profitability is that it is difficult for the managers to comprehend its concepts and its working. It is, therefore, concluded that standard profit should remain the appropriate criterion. However, while employing it, appropriate and generally understood adjustments can be made. For instance; some partial indicators like capital to production reflecting capital productivity, etc. are linked with profitability to reflect real performance of managers.

\section{Enterprise - Specific Criterion Value}

Given the choice of any performance criterion (be it private profit, public profit, labor productivity, and capacity utilization, or anything else) as appropriate for evaluating a particular endeavor, then the still more difficult task remains of selecting a particular criterion value. While the criterion establishes the scale, the criterion values 
I. Mehdi (2016)

Public Enterprise

Volume 22, Issue 1, pp. 92-117, 2016

https://doi.org/pehyj.2016.2201.06
International Center for

Promotion of Enterprises

establishes the point on the scale which distinguishes, say-"bad" from "average" from "good performance". The function of the criterion value, then, is to allow for the plethora of enterprise-specific constraints, which affect the ability of a particular unit, to generate public or private profit. The number of such factors are large, thus, this can be a knotty task. The sources of information which can assist in setting criterion value include:

- Comparisons with similar firms elsewhere,

- Comparisons with the same firm in previous years,

- Professional judgment by third parties,

- Professional judgments at the ministry level, and

- Professional judgment at the enterprise level.

If there are a large number of similar units operating in similar circumstances, then the problem is mechanical. Simply collect data on relevant variables for a sufficiently large number of units and compare it with an individual enterprise. The difficulty with this approach for public enterprises is that the number of "similar" enterprises is usually small. For instance, in 1980s and 1990s, Pakistan had only one integrated steel mill and only two oil refineries. It had four public fertilizer plants but their technology was sufficiently different to make direct comparison difficult. Only in the cement sector there were a reasonable number of similar enterprises in Pakistan. As a consequence, Cement Corporation had the best cost control system in the public sector, precisely because of the ready availability of standards of comparison. The number of observations can be increased by introducing international comparisons, but then the number of control variables increase geometrically. In evaluating cement, in Pakistan it was essential to know that the international standard for operating days is 330 and that many developing countries in fact achieved this level of performance and it could be compared with those of Pakistan's plants. However, other exogenous factors (notably the availability, quality and price of inputs such as energy) differ, making global comparisons difficult. The point is that while comparisons with other domestic or foreign plants can serve as useful partial aids to judgment in setting criterion value, they are in themselves insufficient.

How then is a "similar" enterprise to be found as a basis for comparison? In the entire world, the enterprise most similar to enterprise " $A$ " in year " $t$ " is generally enterprise " $A$ " in year " $t-1$ ". This leads to the use of last year's performance as the criterion value against which this year's performance is judged. The focus is on the trend in performance rather than level. While this is a step in the right direction, it is not a final solution, for two reasons. First, even for single enterprise things change from year to year. Most importantly, prices change. As already noted, this can and should be treated mechanically by shifting to constant price evaluations. However, other changes (e.g., in demand conditions or the availability of inputs) also affect performance and cannot be treated so simply. Moreover, a second factor needs to be considered, namely, that the room for improvement varies from unit to unit. In a plant which has historically been poorly run, a twenty percent improvement in the indicator might require the same level of managerial effort and skill as that required to produce a two percent improvement in the indicator of a plant that has always been well run (Jones, 1981).

"In sum, inter-temporal and inter-enterprise comparisons are essential inputs into the process of setting criterion values, but in the end a subjective professional judgment is required. Third-party evaluations can sometimes be used for this purpose. For a new firm, the project proposal provides some standards. It is also possible to commission detailed internal evaluations by consultants, but this is expensive and should probably be confined to weaker firms. In most cases, the ultimate judgment will have to be made at the corporation or ministry level-in consultation with the enterprise." (Jones, 1981) 
I. Mehdi (2016)

Public Enterprise

Volume 22, Issue 1, pp. 92-117, 2016

https://doi.org/pehyj.2016.2201.06
International Center for

Promotion of Enterprises

\section{Setting Up of Benchmarking and Performance Evaluation System in Pakistan}

\section{Background of Setting Up an Evaluation System}

In line with other developing economies, public corporate sector in Pakistan acquired an important position by the late 1970s. During the period between 1947 and late 1960s, it was considered a well-run sector. Its importance was acknowledged when public corporate sector was discussed as a separate sector of the economy in the Third Five Year Plan (1965-70) of Pakistan (Government of Pakistan, 1965). This was also acknowledged by the fact that each of the major sectors of the economy like industry, agriculture, finance and water, and power etc., was led by a major public corporation. A prominent head of the electricity corporation described that public corporations were widely used in Pakistan to the extent that during this period government was run as "Government by Corporations" (Gorvine, 1966).

The performance of the public corporate sector experienced a major downswing during the 1970s. The primary reason was sudden expansion of public sector due to nationalization in most of the sectors of economy such as Manufacturing, Finance, Medium and Small enterprises etc. This sudden expansion of the public sector was beyond the existing management capacity of the then government. Even in the post-1977 period when policy of nationalization and management of economy through control of "Commanding Heights" was discontinued public sector continued to expand. This was due to gradual completion of projects which were initiated in the earlier period. This resulted in continued performance deterioration and resultant losses and in turn increasing fiscal deficit. The government established number of committees and task forces headed by secretary and finance minister to examine the reasons of their adverse performance and make recommendations. However, implementation of their recommendations could not make a dent on PEs performance. The report which made a major impact on PE sector was prepared in 1981 by a consultant Prof. Leroy P. Jones of Boston University. His report entitled "The efficiency of manufacturing enterprises in Pakistan" examined issues confronted by Public Industrial Enterprise (PIES). It summarized that the PEs management system in Pakistan was antiquated and needed major reform efforts. The report focused only on the public manufacturing sector, its organization, and autonomy structure and recommended a comprehensive reform program (Jones, 1981).

\section{Reforming of SOEs by Establishment of Signaling System for Public Enterprises}

During the period covered by Leroy Jones Report the public industrial sector in Pakistan was managed by the Ministry of Production. The ministry with the assistance of a highly skilled and professional body, i.e., Experts Advisory Cell (EAC) controlled more than 50 operating enterprises through eight holding corporations. This conglomerate comprised the whole of large public industrial sector, i.e., steel, engineering, automobile, chemical, textile, cement, etc.

The report reiterated that internationally, many of the problems of the public enterprise sector were traceable to inadequacies in the signaling system. This was because public enterprise goals were difficult to specify due to the problems of multiple objectives (commercial versus non-commercial) and plural principles (different control organs having different perceptions of what the goals should be). If goals could not be specified, then "good" performance could not be distinguished from "bad", managers could not be rewarded on the basis of performance, and inefficiencies could result. 
I. Mehdi (2016)

Public Enterprise

Volume 22, Issue 1, pp. 92-117, 2016

https://doi.org/pehyj.2016.2201.06
International Center for

Promotion of Enterprises

It was also indicated that public enterprise was a hybrid, sharing characteristics of public and governmental institutions and private enterprise. Like government, some of its goals (non-commercial, for short) were difficult to quantify; like a private enterprise, some of its objectives (commercial, for short) were readily quantifiable. If "poor" commercial performance could readily explain away in terms of "non-commercial" objectives and if no effort was made to distinguish between legitimate reasons for poor commercial performance (e.g., government pricing policies) and illegitimate reasons (e.g., in-competence leading to high cost), then even the quantifiable objectives lost their power for guidance, motivation, evaluation and control. The enterprise then, in effect, became just like a government agency rather than a hybrid. The public enterprise manager played a game without a score (Mehdi, 2014).

Jones' report (1981) indicated that in Pakistan's public industrial Enterprises (PIEs) there was a poor autonomy structure which was over-controlled and there was little delegation of power. Restructuring the autonomy structure, therefore, was the pre-requisite for reform of PIES. In the proposed autonomy structure, the central office, i.e., Ministry of Production with the assistance of EAC, was expected to-operate like head office of a multi-national where barring strategic areas, as illustrated in earlier paras of this paper, remaining areas were to be delegated to subordinate units. However, if the autonomy was to be efficiently and permanently delegated to the enterprises, then accountability had to be insured by a signaling system which specified and rewarded socially desirable behavior. In the following paras the main features of Signaling System are summarized and an account of its operations in Pakistan is expounded (Mehdi, 1984).

\section{Main Features of Signaling System Operations}

The main features of Signaling System operations (Mehdi, 1984, 1988) are the following:

- Selection of performance criteria,

- Selection of units by which performance is to be measured (e.g. \% increase in profitability),

- Assignment of weights to reflect relative importance of chosen criteria,

- Negotiation and determination of targets to demonstrate strong and weak performance. For this a performance scale (A, B, C, D, and E targets) rather than one target is negotiated so that the unit can be categorized in any one of the five grades of performance,

- At the end of the year, based on the audited accounts, the achievement of the unit is compared with the original targets, and

- Following this appraisal, units are categorized in one of the five classes so that the predetermined bonus amount, linked with each grade, can be allocated to the chief executive officers who in turn distributed it among their managers.

\section{Commencement of Preparations for Operations of the Signaling System}

Having developed the basic structure of performance evaluation, i.e., selection of performance criteria and criterion value, the EAC manager's first task was to prepare for commencement of operations of signaling system. The most important task in this regard was to prepare for target negotiations. In this pursuit EAC developed formats for collecting information on the budgetary proposals. The focus of these formats was to seek information to negotiate targets on the basis of real performance. Some of the important elements of the new budgetary formats were to collect following information: 
- Break-up in volume and prices all the values e.g. sales and cost of sales, etc.,

- Details of gross margins of individual sales items, and

- Information on price trends of individual items of sales.

Seeking such information from large number of enterprises, where some of them did not possess adequate skill of accounting and more specifically cost accounting, was a challenging task. It took more than a year for EAC to develop now budgetary formats. Subsequently, the formats were communicated to PE managers; who were also briefed/ trained by EAC technicians how to fill them.

\section{Development of Protocol for Negotiating Target}

EAC technicians developed a well thought out protocol to negotiate targets. It was an important exercise to attain the objective that the target shall be negotiated by EAC with the management of enterprises and they will not be imposed on them. To attain this objective EAC thoroughly examined each and every budgetary proposal so that they are able to raise appropriate questions and come to an agreement purely on basis of technical and professional considerations. EAC conducted negotiations at the level of Chief Executive and his team. The negotiations always culminated in a standard, well thought out and readable agreement. The standard format of the agreement is provided in the Appendix. The target negotiations exercise was developed and systematized over a period of time and in a gradual manner. The target negations were conducted within following protocol:

\section{Protocol Adopted by EAC for Negotiating Targets}

The target setting should be carried out in a participative process. Without a participative approach, targets tend to take the form of formal directives which are often overtly accepted and covertly resisted. Keeping this in view EAC finalized targets in consultation with the Chief Executive, respective Holding Corporation, and with the approval of the Ministry.

Targets were explicit and clear-cut so that the performance aims were not hidden behind the vague objectives. Moreover, targets were neither too low nor too high to avoid emanating wrong signals to the managers. It was important to keep in view the general economic environment of the organization that the unit management was expected to experience during the coming year. It was also ensured that targets were large enough to generate surplus which was significantly more than the amount required for distribution by way of incentive bonus.

It was acknowledged that public enterprise managers are entrusted with various social tasks. While negotiating targets it was to be ensured that social costs should not be a source of alibi for poor performance. EAC therefore, attempted to verify if a certain cost is a genuine social cost and then adjusts targets to accommodate it.

Following the completion of the preparatory task, the process of target negotiations was initiated. The target setting was conducted on the principles described below.

\section{Principles of Target Settings}

- What were the original objectives, designed capacity, and expected profit of the enterprise?

- What has been the performance of the enterprise in the past year? 
- What is the achievement level of similar undertaking in the private sector?

- What are the standards achieved by similar undertaking in other selected developing and developed countries?

- What are the various financial and physical constraints expected to be experienced by an enterprise during the year?

- What is the macro-economic environment which is going to influence the demand and supply position of the inputs and outputs of the enterprises?

After commencing the target negotiating exercise with a canonic approach, EAC gradually improved the process of target setting by employing more innovative tools and methods including various new techniques of benchmarking.

\section{Modifications and Improvisation in Setting Target and Evaluation}

Having experienced relatively efficient target setting and evaluation thereon, the managers of EAC reviewed the potency and impact of target setting and identified areas where improvements could be made. In fact, one of the major features of the operations of signaling system was that its managers remained open to suggestions and were more than willing to modify and change as when considered needed.

After the first four years of performance Evaluation and target setting experience the systems performance was reviewed both, internally by the EAC managers as well as experts such as Mary Shirley (1989) John Nellis (1989) of the World Bank. The external professionals carried out an in-depth evaluation of individual aspects of the system well as its overall effectiveness. While, evaluating the process of target negotiation following observation and recommendations were made:

"One way to improve in depth knowledge of the companies might be to bring in outside experts from the academic or business communities, as is done in Korea. Or the EAC might rely more on the technical expertise in the corporations. There are some problems with these approaches: it could be harder and slower to reach agreement with a lot of outsiders involved, while the corporations have a vested interest in their enterprises earning a good score. Also the EAC has acquired skills in preparing and negotiating targets that would be lost if there were separate professionals involved. Nevertheless, the EAC could use some specialist knowledge, perhaps provided by a team of advisors brought in on a short-term basis at EAC discretion. Consideration should be given to expanding the EAC budget for this purpose. Also, the EAC should develop international benchmarking for comparison." (Shirley, 1989)

\section{Reforms in Target Setting}

In order to make the system more effective and bring increasing optimality in the negotiation of targets and their evaluation some major steps were taken. They were as follows:

\section{Benchmarking}

To bring in greater optimality in the target negotiation EAC formulated the concept of benchmarking-both national and international benchmarking. 
I. Mehdi (2016)

Public Enterprise

Volume 22, Issue 1, pp. 92-117, 2016

https://doi.org/pehyj.2016.2201.06
International Center for

Promotion of Enterprises

\section{Strategic Planning}

Originally the signaling system, aimed at improving performance of PEs in static situations. It focused on their operations in short term i.e., one year. To address the issues related to period beyond one year the scope of signaling system was enlarged by supplementing it with strategic planning. Thus, the fortified signaling system focused on improving performance of PEs both in short as well as long term.

\section{Diagnostic Report}

It was noted that budgetary proposals were prepared with certain assumptions. During the course of the year unforeseen developments, such as changes in prices, took place. Consequently, compared to the originally conceived results there were frequently different outcomes because of unexpected circumstances. These changes frequently were outside the control of managers. Therefore, a concept of diagnosis of performance trends was introduced. At the end of the year, based on the audited reports of the PEs, an in-depth evaluation was carried out by EAC. The objective was to identify what was the real contribution of managers and what was the effect of non-controllable factors. An annual diagnostic report therefore was prepared which helped in grading the managers according to their real performance.

A brief account of the three improvisations of the signaling system is described below.

\section{Benchmarking}

The process of target negotiations commenced at EAC with somewhat rudimentary facilities, information and knowhow. The benchmarking tools were employed from the beginning but owing to inadequate facilities the data base of performance of similar enterprises was not collected systematically. Based on the recommendations emerged from internal reviews as well as from those emanated from on outside sources, such as Mary Shirley's paper (1989), a systematic application of benchmarking was introduced gradually. A group of researchers was constituted to develop this information base in a more systematic manner. An account of various concepts of benchmarking, tools, and methods employed by EAC in setting up the targets is given as follows.

\section{Concept of Benchmarking Employed by EAC}

Traditionally, performance measures have been comparison of the same organization at different times in the earlier period. It gave good indication of the improvement rate, or otherwise. It could demonstrate that, although the organization was improving, the competition was improving faster. In a changed environment, various models of benchmarking were developed in the public enterprise sector to determine how well a business unit, division, organization or corporation was performing compared with other similar organization (Mehdi, 1997; Jorion, 2007; Dahlberg \& Isakson, 1996).

\section{Advantage of Benchmarking}

Benchmarking emerged as a powerful management tool because it overcome the assumption that can be summed up as the following mode of thinking "the way we do it is the best because this is the way we have always done it". 
I. Mehdi (2016)

Public Enterprise

Volume 22, Issue 1, pp. 92-117, 2016

https://doi.org/pehyj.2016.2201.06
International Center for

Promotion of Enterprises

Benchmarking opened organizations to new methods, ideas and tools to improve their effectiveness. It helped crack through resistance to change by demonstrating other methods of solving problems than the one currently employed and to demonstrate that they work, because they have been used by others.

\section{Experience Curve}

The experience curve was developed by the Boston Consulting Group in 1966. It is based on the hypothesis that total per unit costs decline systematically by as much as $15-25 \%$ every time the cumulative production (i.e., "experience") doubles. It has been empirically confirmed by some firms at various points in their history. Costs declined due to a variety of factors, such as the learning curve, substitution of labor for capital (automation), and technological sophistication. Following were the basis of such assumption:

- A company can always improve its cost structure,

- Competitors have varying cost positions based on their experience, and

- Firms could achieve lower costs through higher market share, attaining a competitive advantage.

Some of the generally accepted tools and concepts employed by EAC to improve targets are described below.

\section{Best Practice}

The best practice was a method or technique that had consistently shown results superior to those achieved with other means, and that was used as a benchmark. In addition, a "best" practice could evolve to become better as improvements were discovered. Best practice was considered by some as a business buzzword, used to describe the process of developing and following a standard way of doing things that multiple organizations could use.

Best practices were used to maintain quality as an alternative to mandatory legislated standards and could be based on self-assessment or benchmarking. Best practice was a feature of accredited management standards such as ISO 9000 and ISO 14001.

\section{Internal Benchmarking}

Internal benchmarking was used when a company already had established and proven the best practices and they are simply shared. Internal benchmarking also may be necessary if comparable industry was not available.

\section{Competitive Benchmarking}

Competitive benchmarking was used when a company evaluated its position within its industry. In addition, competitive benchmarking was used when a company needed to identify industry leadership performance targets.

\section{Strategic Benchmarking}

Strategic benchmarking was used when identifying and analyzing world-class performance. This form of benchmarking was used when a company needed to go outside of its own industry 
I. Mehdi (2016)

Public Enterprise

Volume 22, Issue 1, pp. 92-117, 2016

https://doi.org/pehyj.2016.2201.06
International Center for

Promotion of Enterprises

\section{Standards Benchmarking}

Standard, or a set of standards, was used as a point of reference for setting targets for evaluating performance: Benchmarking was drawn from a firms own experience, from the experience of other firms in the industry, or from government policy requirements. For instance, in the public industrial enterprise sector in Pakistan following a government decision each $\mathrm{PE}$ was expected to accrue $1 \%$ of total sales on research and development. In the absence of the competitive pressures for research in the private sector it provided significant incentive to PEs to focus in this area.

Above is a short and quick account of benchmarking which were employed in EAC's performing evaluation system in the subsequent phase of target setting exercise. This chronicle has shown only those concepts and tools of benchmarking which were employed in the performance evaluation system for reforming and improving the effectiveness of setting up targets of public enterprises in Pakistan. It also indicated that once the process of systematic benchmarking was introduced Quality of target negotiation improved significantly.

\section{Strategic/Corporate Planning}

The technicians of EAC in the periodic review of performance evaluation system identified number of tools and ways and means to improve target setting. In this pursuit, they identified a system of corporate planning based on the model developed by a world-renowned consulting firm. This system focused on achievement of objectives of individual enterprises both in short, medium, and long term. This was a major shift from the original signaling system which had focused only on the performance in static situation, i.e., in one-year period. In the new strategic planning system, the managers' vision was enlarged. They were made to prepare themselves to compete in medium and long term both locally and globally by way of restructuring at all levels, i.e., organization, finance, plant and machinery, and HR, etc.

Until recently the focus of attention in target setting of the signaling system was on improving performance in short period. While this indeed helped in motivating managers to improve performance during the period, this effort frequently was at the expense of the long term interest of enterprises. This can be seen in following two cases:

1. Managers some time overlooked the repair and maintenance schedule to achieve the annual target.

2. The managers' focus was on performance during their tenure of service which was often for three years' period. Therefore, frequently, they did not pay attention to actions such as research and development etc., which were to produce results in period of time beyond their tenure.

In order to broaden the horizon of interest of managers, they were motivated not only to continue focusing on real performance in short period but also to keep into consideration the long term interest and requirements of the enterprise. They were encouraged to develop strategic plans to aim at long term objectives of enterprises.

\section{Strategic Planning Model of EAC}

The strategic planning model adopted by EAC was initially acquired from Arthur D. Little International, Inc. (1987) consulting firm. This model was then modified to suit Pakistani's management environment. The strategic plan model adopted by EAC was based on two categories of assessments: Industry maturity and competitive position. 
I. Mehdi (2016)

Public Enterprise

Volume 22, Issue 1, pp. 92-117, 2016

https://doi.org/pehyj.2016.2201.06
International Center for

Promotion of Enterprises

The combination of two assessments indicated the strategic condition of an enterprise. A strategic plan was evolved on the basis of this finding.

In the analysis of competitive intensity, future possible profitability of the industry was indicated. It analyzed the competitions in the industry and identified steps required to retain its market share and future trends of the competition. It was also supplemented by corporate strategy which involved answering a key question from a portfolio perspective: "What business should we be in?" Business strategy involved answering the question: "How shall we compete in this business? These questions/issues were addressed by strategic plan which was prepared on the basis of Strategic Business Unit (SBU) which was a completely independent unit based on competitive and market characteristics rather than legal and organizational consideration. A separate plan of SBU is prepared by the combination of two critical elements of planning in EAC model: i.e. Competitive position of SBU and maturity of related industry. Following is an account of the planning in EAC model.

\section{Assessment of Maturity}

Once the SBU and its principal segments are defined, management assesses the maturity of relevant industry and its growth potentials and the stability and predictability of its operations and financial performance. We distinguish between four stages of maturity: embryonic, growth, mature, and aging. Knowledge of maturity is important for success in an industry. For instance, in growth industries, marketing is often the key success factor; in mature industries, production economics are often the key.

Knowing the maturity of the industry should help to focus on analyzing the strengths and weaknesses of an SBU and its competitors. Maturity also has an impact on the appropriate style and system of management. For instance, embryonic industries require a more flexible attitude to risk and a less "systematic" approach than aging ones. Maturity also has a direct relationship with risk, in that less mature industries are often less predictable and therefore entail greater risk. The maturity of the industry and its segments becomes one factor in assessing strategic condition

\section{Assessment of Competitive Position}

An analysis of competitive position considers the relative effectiveness of the SBU and its competitors in the market places in which they compete. The current market share of each SBU is considered, along with its rating against the criteria which must be met if the unit is to gain competitive advantage. These criteria (success factors) are derived from a consideration of the basis of competition in the relevant industry. Analysis of a competitive position therefore helps to identify businesses which, say, enjoy a high market share but which are currently poorly situated to maintain that position, and those which were set to gain a higher market share in future, as they score well against the key success factors, despite possibly having a low current market share.

\section{Competitive Intensity}

By analyzing the competitive intensity of a business unit, management can shed light on the likely direction and future profitability of that industry and on the freedom of participants to select successful strategies. The internal rivalry between participants in the industry is studied, so as to determine competitors' possible reactions to strategies. Other key aspects also affect, and can dictate, strategies and profitability potential-such as the threat of new entrants, the threat of substitute products and the bargaining power of suppliers and customers. 


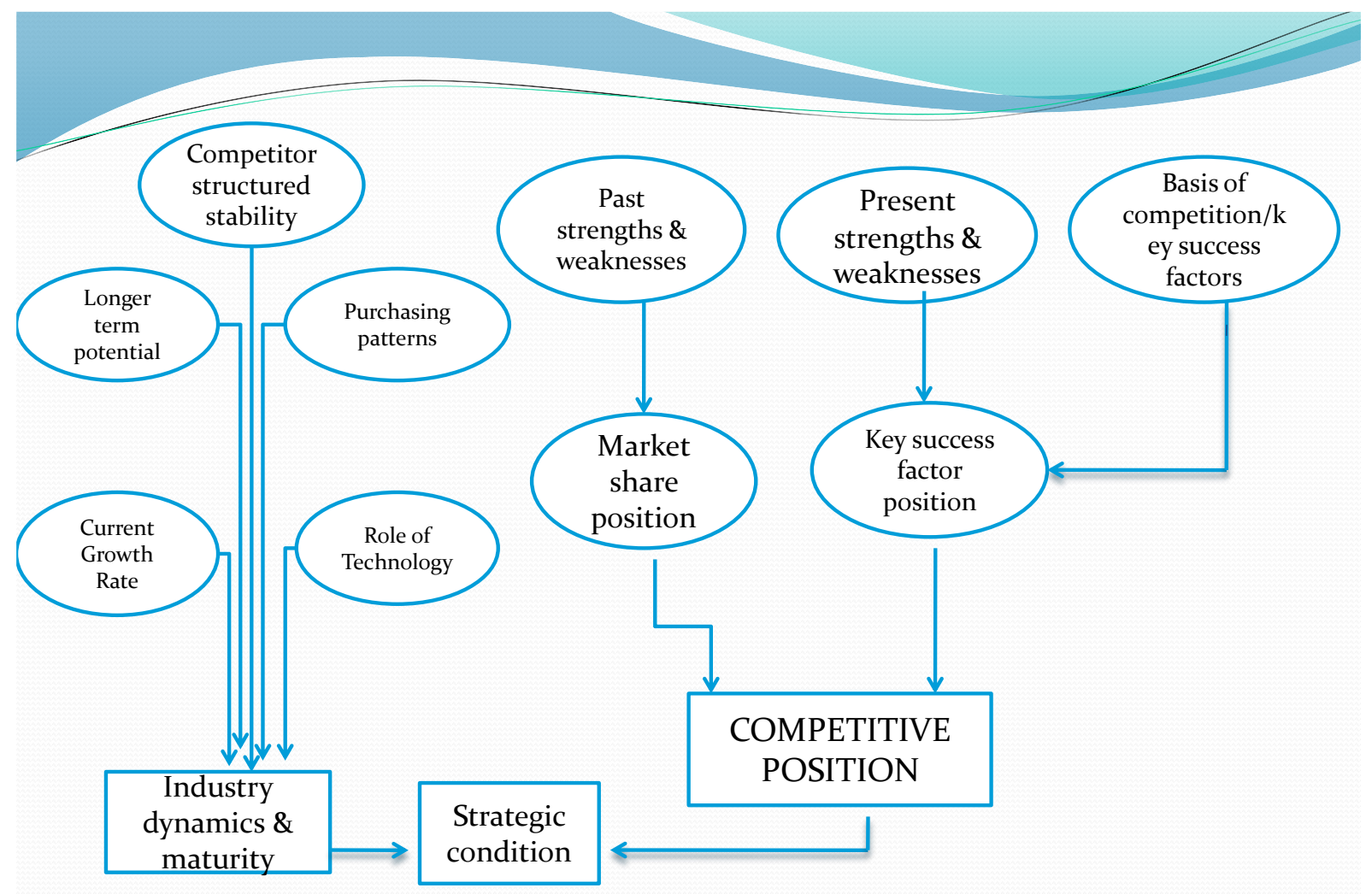

Note. Source: Arthur D. Little International, Inc.

Figure 1. Planning system for an individual strategic business unit. 

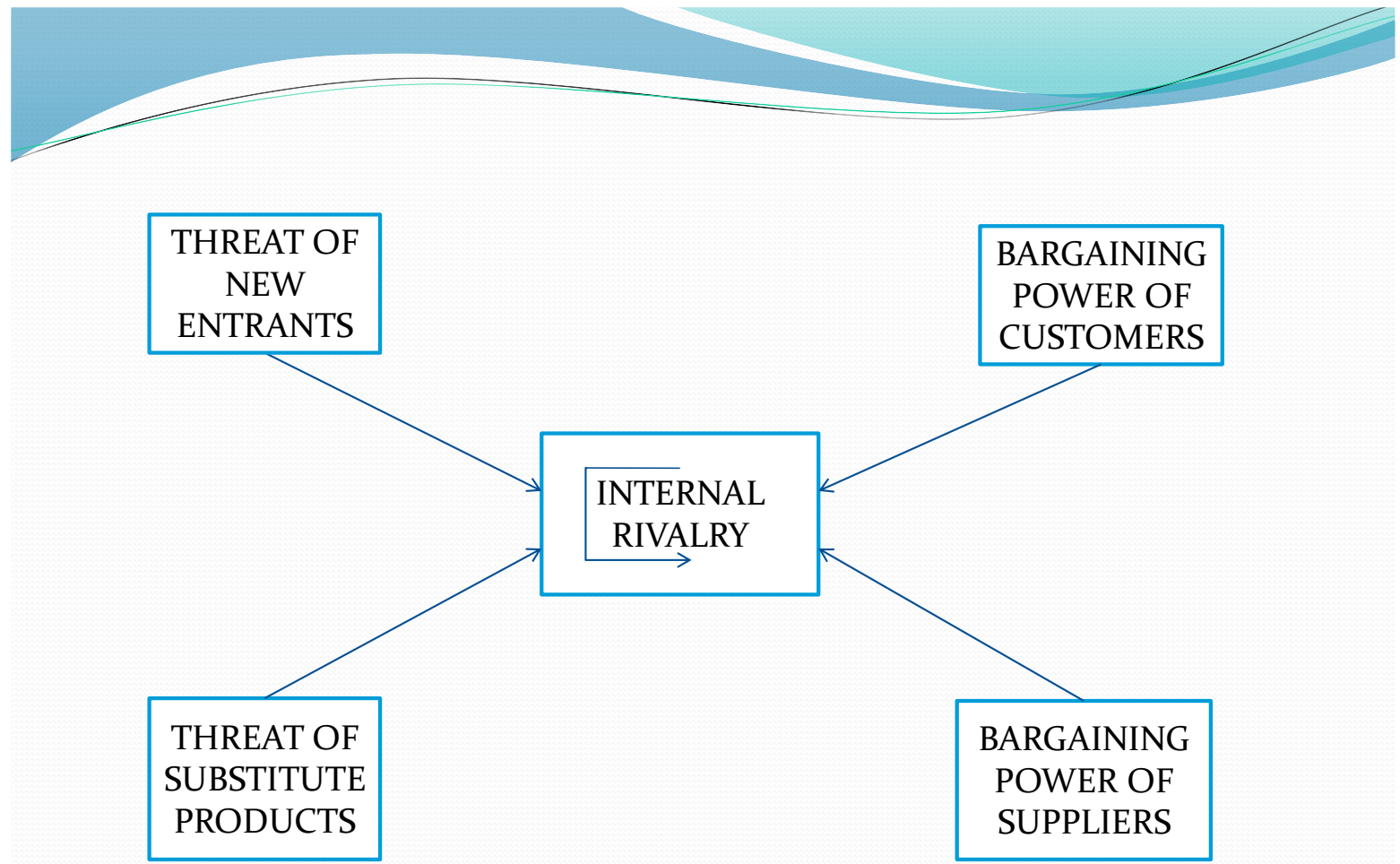

Note. Source: Arthur D. Little International, Inc.

Figure 2. Competitive industry.

\section{Key Factors in the Assessment of Competitive Intensity}

Assessing the intensity of competition is important in SBU planning. It affects the SBU's room for maneuverability in current activities, its profitability beyond the short term and influences the way it competes in its segment. It also indicates the extent to which competitors are likely to react to strategies.

There are five elements that determine how intense the competition in the industry is or could be. The effect of these elements is to be judged by considering the following questions:

- Internal rivalry: How would your competitors react to a major initiative by you, e.g. to increase sales volume by cutting prices?

- Threat of new entrants: How easy is it for a company to enter your industry and take some of your market share? What barriers to entry (economies of scale, product differentiation, capital requirements, etc.,) exist? 
- Bargaining power of customers: How easily can your customer go elsewhere if you cannot provide the products and services he desires? How important is the industry's products to its customers? Are customers price-sensitive?

- Bargaining power of suppliers: How you have a supplier (or group of suppliers) on whom you are dependent, with little alternative? How important to the suppliers is the industry as a buyer? Is there a cost incurred in switching suppliers?

- Threat of substitute products: To what extent can your product be replaced by another product or another way of doing things and is it likely to happen?

\section{Analyzing the Competitive Position}

Analyzing the competitive position gives an indication of future market share and profitability in a market environment. Determining competitive position, along with the competitive intensity of the business, is essential for understanding the freedom of strategic movement of each competitor within the industry.

Market share alone is insufficient as a measure of competitive position because:

- Although market share was clearly a key determinant of competitive position, its importance varied with industry maturity, and

- Market share today reflects past strengths, weaknesses and strategies; similarly, future market share will be influenced by today's strengths, weaknesses and strategies.

An SBU's present competitive position and, therefore, the outlook for its future market share and profitability is determined by two main factors:

- Its present market share, which is itself a result of past strengths and weaknesses, and

- The rating of the SBU against the key success factors.

\section{Assessment of Strategic Condition and Selection of Strategies}

By combining findings from the analysis of industry maturity and competitive position, we could assess strategic condition. This indicates the degree of strategic freedom which an SBU could enjoy. For instance, a strong competitor in a growth industry has wider range of strategic options open to him than a weak competitor in an aging industry. Understanding present strategic condition could ensure that the functional strategies selected for the future are individually and collectively consistent. The combined effect of the selected functional strategies gives out the strategic thrust. The thrust should be consistent with the strategic condition and also compatible with the mission of the business. The mission is expressed in a short overall statement of the fundamental purpose of the business and its role in the industry. Each of the functional strategies is directed toward a clearly stated strategic target. Indeed, each of the strategy is implemented by a well thought-out action plan.

The introduction of strategic planning clearly introduced a new dimension to signaling system operations. The major impact was indeed, on the target setting process. The manager of PEs focus was enlarged to incorporate the long and medium term objectives of the enterprise. The targets set for the medium and long term are achievable on basis of efficient implementation of plan and actions which are worked out for the current period. The implementation of the 
identified action plans has become part of the target negations process. For instance, to achieve a profit by new investment in x years, certain actions have to be taken in year1 which is the current year. This can become part of agreed targets for the current year.

\section{Diagnostic Report}

After negotiating targets for the year, EAC monitored performance during the course of the year. At the end of the year as a first step of evaluating performance, PE accomplishment of the year was placed against the pre-determined target scale. Based on this evaluation, the company was placed in one of the five categories: A, B, C, D, E. Each category was also linked with the following specific incentive rewards:

- Qualified the enterprise three-month bonus,

- Two months,

- One month,

- 15 days, and

- Nothing.

However, EAC improvised evaluation process by initiating the preparation of a diagnostic report, (EAC). The report basically aimed at in-depth evaluation of enterprise performance. The performance was broken up initially on two considerations: based on identification of controllable and uncontrollable factors. It distinguished the real performance of managers against the one achieved as a result of wind fall or other uncontrollable reason. For instance, during the year the prices may have been changed following the government policies or there may have been the problem of unforeseen load- shedding of electricity. These unforeseen and unbudgeted factors are taken into consideration for arriving at the real performance of managers and grade them accordingly.

\section{Performance Evaluation of Signaling System}

It is critical to assess what has been the impact of target based performance evaluation system operations on the performance of PEs which were managed under its purview.

The signaling system was applied on most of the public enterprises under the Ministry of Production. The system was based on following key assumptions:

- Manger can be given a clear perception of their objectives,

- PEs performance in Pakistan can be improved,

- Managers can control enterprise performance,

- PE managers will respond to incentives (monetary and non-monetary),

- Managers can be given ready access to information and other resources necessary to improve PE performance, and

- Performance can be measured objectively and fairly, hence its evaluation will send the right "signals" to managers. 


\section{Performance Trend as per Current Prices Profits}

As per approved performance evaluation system, Performance grades and incentives were awarded principally on the basis of private profits after taxes in current prices. On the basis of that indicator Industrial Public Enterprises (IPEs) performance generally improved. Thirty-three IPEs were in the system for its entire three years of operation, of which 19(or about 58percent) improved their private profits after tax, from 100 million Rupees in 1982/83 to 617 million in 1985-86. Thus, the majority of these PEs showed an improvement as per the main indicator employed in the targeting system. After three years the total profits of the 33 PEs in the system were almost twice what it had been before the system began (Table 1).

Table 1

Performance of PEs under Signaling System for Three Years: Profits (millions of Rupees)

$\begin{array}{llll}1982 / 1983 & 1983 / 1984 & 1984 / 1985 & 1985 / 1986\end{array}$

33 IPEs in system for

$344.14 \quad 467.10 \quad 937.81$

684.00

Three year.

19 IPEs with profit

$-100.75$

221.08

717.45

616.74

improvements

14 IPEs with profit

444.89

246.08

220.36

67.30

deteriorating

Note. Based on data retrieved from the Expert Advisory Cell's "Annual Reports on Performance of Public Industrial Enterprises," various years.

\section{Trends of Attainments of Grades}

Similar trend of performance improvement is observed in the distribution and trend of grades achievement. It is reflected in the table I which shows that higher grades were awarded in 1984-1985, 1985-1986, and 1986-1987 compared to the first year, i.e., 1983-1984.

Table 2

Performance of IPEs in Terms of Grade Achievement

\begin{tabular}{|c|c|c|c|c|c|c|c|c|}
\hline & \multicolumn{2}{|c|}{$1983-1984$} & \multicolumn{2}{|c|}{ 1984-1985 } & \multicolumn{2}{|c|}{$1985-1986$} & \multicolumn{2}{|c|}{$1986-1987$} \\
\hline & $\begin{array}{c}\text { No. of } \\
\text { units }\end{array}$ & In $\%$ & $\begin{array}{c}\text { No. of } \\
\text { units }\end{array}$ & In $\%$ & $\begin{array}{l}\text { No. of } \\
\text { units }\end{array}$ & In $\%$ & $\begin{array}{l}\text { No. of } \\
\text { units }\end{array}$ & In $\%$ \\
\hline A & 7 & 17 & 13 & 23 & 16 & 35 & 13 & 31 \\
\hline B & 7 & 17 & 9 & 16 & 9 & 19 & 6 & 14 \\
\hline $\mathrm{C}$ & 6 & 15 & 5 & 9 & 4 & 9 & 4 & 10 \\
\hline $\mathrm{D}$ & 5 & 12 & 2 & 4 & - & - & 2 & 5 \\
\hline
\end{tabular}




\begin{tabular}{cccccccccccc}
\hline E & 16 & & 39 & 27 & & 48 & 17 & 37 & 17 & 40 \\
Total & & 41 & & & 56 & & & 46 & & & 42 \\
\hline
\end{tabular}

Note. Based on data retrieved from the Expert Advisory Cell's "Annual Reports on Performance of Public Industrial Enterprises" various years.

\section{Assessment of Other Possible Influences on Performance of Pes}

While there appears to be direct positive impact on the performance of PEs, an attempt was made to assess if other factor were also solely or partially responsible for the changes. Following were some of the probable influencing factors:

- Change in prices,

- Changes in the macroeconomics environment,

- Changes in markets,

- Changes in PEs liquidity positions, and

- Changes in management due to changes in the supervisory environment of the PEs and /or the signaling system.

Other possible explanations which were rejected because they do not fit with the circumstances are:

- A drop or rise in labor unrest (no significant change occurred),

- Improvement or deterioration in the supply of inputs or services such as electricity, water, transport (PEs experiencing problems saw little change), and

- Technology change (there were no significant change in the technology used in the sample enterprises during this period).

- A change in liquidity was another explanation that was considered and rejected. Levels of liquidity were low in most of the sample firms and showed little change during 1983-1984 or 1984-1985.

Some of the critical factors mentioned above are analyzed as follows:

\section{Changes in Market}

Competition could explain an improvement in profit and efficiency if the PEs react to competitive pressures by working harder to cut costs, expand production, improve quality, etc. In contrast, if the PEs cannot or will not respond, the result will be deterioration in performance. Competition increased in Pakistan during the period under review, thanks to trade liberalization, easier private entry into previously public activities, and the earmarking for credit for the private sector. Competition has had a favorable impact on some public firms which were striving hard to improve efficiency and retained their market. However, competitive pressure did not seem to be the main explanation for the efficiency improvements in the firm covered by the signaling system. Some of these firms, such as HMC and PECO two engineering enterprises, have faced competition since before the period under examination. Others, such as the fertilizer plants and the refinery, faced no change in competition but, nonetheless, showed efficiency gains. In most cases where PEs have faced an increase in competition the result during the short period under examination has been deterioration in performance. 
I. Mehdi (2016)

Public Enterprise

Volume 22, Issue 1, pp. 92-117, 2016

https://doi.org/pehyj.2016.2201.06
International Center for

Promotion of Enterprises

\section{Changes in Management}

In several of the sample companies, the improvement in performance seems to be explained in large part by management changes. This is especially true for the four companies which show efficiency gains above their past trends. Probably much of the improvement in the performance of Sind Alkalis could be attributed to a change in the management team at the start of the period. In other cases, the same managers strove harder to curb costs and expand output. For example, Sind Alkalis increased its soda ash capacity utilization from 38 to 90 percent; thus, the argument that the efficiency improvements were partly due to the system cannot be ruled out since none of the other explanations fully explain the efficiency improvement.

\section{Issues Faced in the Operation of Performance Evaluation System}

The operation of performance evaluation system has highlighted the complexities involved in the systematic assessment of public enterprise management performance. Some of the critical issues faced by EAC in operating the performance evaluation system were as follows (Jones \& Mehdi, 1985):

- $\quad$ Pricing Policy: Public sector enterprises sold their products in two pricing regimes, i.e., prices controlled by government and prices determined by the market. In 1983-84, the first year of operation of the system, more than $65 \%$ of the total sales of the public sector industries were directly or indirectly controlled by the government pricing policy. PEs were selling their products at government fixed prices faced the problem of accommodating the government instructions of setting up targets of private profitability and at the same time ensuring motivation for improving performance. In such cases where prices were fixed and supply was constrained, profit targets were supplemented by assigning some weights to capacity utilization and conservation of costs by using selected physical consumption ratios.

- Profit after tax as a primary criterion also presented a problem in forecasting the tax at the beginning of the year since it varied with various levels of profits. EAC established targets on the basis of assumed tax rates and evaluated performance against that basis.

- Non-operating income (selling of scrap and income from financial investment, etc.) frequently was a major source of profit. Assessment of whether this income was owing to the efforts of the management or by a management policy decision created numerous debates at the time of evaluation.

- Additional costs on account of social obligation such as construction of a road for the benefit of the local population, etc., called for strict assessment of the cost and its validity. This was adjusted to profit before the evaluation of the performance.

- The problem was also experienced due to costs and incomes attributed to the previous years. EAC's target clearly stated that targets relate to the performance attributable to the year under review only. Evaluation exercises, therefore, remained indifferent to previous period.

- The emphasis on maximization of profit also led to a problem of management making efforts to attain the targets for the year by ignoring the long term interest for the year by ignoring the long term interest of the 
enterprises specially maintenance program etc. In view of the importance of these elements EAC made the targets conditional to the maintenance schedule provided for in the units' budgets.

- The setting up of targets on the basis of profitability (profit/assets) led the PE management's towards extremely profit orientation. It was noted that managers aimed only at the elements which influenced immediate profit and ignored critical areas like asset management which may affect their performance in the subsequent period. Consequently, after the EAC's first year's evaluation of results on the basis of profitability number of chief executives (some of whom were senior accountants and financial experts) were surprised to see that they may have performed well in terms of profit but owing to their inadequate asset management, i.e., increase in current assets such as receivable etc., their profitability target could not be attained.

- In arriving at optimal targets for the units' information regarding production capacity was necessary. However, finding the capacity of some units presented an issue since an accurate information regarding this was not available due to:

- Age of the units: in course of time either the unit deteriorated the original capacity; or it was increased owing to new investments.

- There was a tendency to indicate low capacity due to past capacity taxation policy. EAC had to carry out special exercise just to determine capacities of certain units.

- In order to ensure that credit is given to all efforts made by managers, evaluation of performance was carried out at two stages. In the first instance actual achievement of the unit was placed against originally negotiated target. Secondly, in consultation with concerned holding corporations the uncontrollable and unforeseen elements of units' managements were identified and the original assessment was adjusted accordingly. For instance, in case of a fertilizer unit the government had decided to stop supply of natural gas for three months because of shortage of energy in the country. Thus the targets of the unit were adjusted for an operation of nine months before final grading of performance. Subsequently, such issues were addressed in the diagnostic report.

- Some of the firms were also constrained in their choice of markets, products and suppliers. Not surprisingly, import substituting enterprises like oil refineries it must satisfy domestic demand before exporting.

- Government imposed social welfare objectives placed another burden on the PEs. It sometime reduced management's flexibility to cut costs. For example, one company was required to train five people for every one person they intended to hire. Plants located in remote areas at government behest had to provide education, housing, health services and transportation to employees as well as bear added transport costs. Again such issues were addressed in diagnostic report.

- Finally, management was constrained by the inherited capital stock. Management could still improve operating efficiency within that constraint, but the task could be considerably harder when the plant was grossly under or oversized or the equipment was antiquated and worn out. Subsequently, strategic plans addressed number of such issues. 
I. Mehdi (2016)

Public Enterprise

Volume 22, Issue 1, pp. 92-117, 2016

https://doi.org/pehyj.2016.2201.06
International Center for

Promotion of Enterprises

\section{Managers Attitude towards the System}

A preliminary survey of the managers' attitude toward the signaling system indicated that it had at least been able to draw their attention towards operational efficiency. The CEOs of PEs were conscious, to say the least, of year-end evaluation and grading which made them accountable for their performance. Indeed, the reaction of PEs managers ranged from a positive support to skepticism to strong opposition towards the system. The reaction of managers towards this system divided them into two classes:

- Managers who were favorably inclined towards this system, and

- Managers who were skeptical towards this system.

\section{Managers Reacting Positively}

The reasons for some managers supporting the system were as follows:

Managers whose units have been generating profit for a number of years had grievances that there was no method and system for acknowledging their achievements. The issue had become important since workers' bonus was to a large extent determined by the profit-earning performance of the unit and they were getting away with as much as ten bonuses. As a consequence, often managers at the junior level were getting less financial emoluments than some workers. Incentive system provided a method of rewarding bonus to the officers in profit earning units.

Managers of some units especially those where prices were fixed found a way of demonstrating their good performance. For instance, in case of a petroleum unit, in the past their managers had argued that their unit was working at a high level of efficiency. However, the conventional performance indicators, such as profit, could not demonstrate this irrespective of its performance. EAC in its efforts to motivate management to improve productivity evolved a set of criteria of evaluation which along with targets to maximize profitability (by reducing assets, i.e. inventory and receivables, etc.) assigned weights to productivity through partial indicators such as capital production etc. which showed their real performance and achievements.

Generally, it was experienced that the managers of process industries were more enthusiastic towards the system than those in the batch industries. One of the reasons of this was that most of the process industries were selling in a supply constrained situation where they aimed at maximization of production. As against this, batch industries were operating in a competitive environment where the performance was largely determined by the market. Since marketing was one of the weakest areas of the public sector managers, the managers of these units generally felt uneasy and uncertain while negotiating target for sales. However, among those units those with a profit making record found the evaluation system helpful to them.

The reaction toward the system was also very largely dependent on the personality of the managers. Managers, who had the drive, ambition, and endeavor, should their enthusiasm towards the system; indeed, these managers were also the most difficult ones to negotiate targets with.

\section{Skeptical Managers}

The managers who were consistently in the E grade were skeptical. However, none of them ever disagreed with results. 
I. Mehdi (2016)

Public Enterprise

Volume 22, Issue 1, pp. 92-117, 2016

https://doi.org/pehyj.2016.2201.06
International Center for

Promotion of Enterprises

\section{Conclusions}

By and large various professional reports were positive towards the signaling system (Mary Shirley 1989, Jones \& Mehdi 1985). One of the major arguments were that for the first time there was a system which acknowledged managers' efforts. Perhaps the best conclusion about effectiveness of the signaling system in Pakistan is reflected in the concluding remarks of a World Banks report which recommended its application to other countries (Mary Shirley, 1989).

"The Pakistan signaling system, for all the flaws discussed here, represents a major advance in holding managers accountable for performance. In many developing countries, there is no attempt to develop targets, and no meaningful reporting on PE results; good managers went unrewarded and bad managers unsanctioned. As a result, the interest in the Pakistan signaling system is very strong and a number of countries are considering introducing something similar, including the Philippines, Egypt, and Venezuela. Korea already has a similar system in place. This assessment of the experience in Pakistan provides a number of lessons for such countries about the potential costs and benefits and how to adapt the system to different circumstances".

\section{References}

Advisory Cell. Diagnostic Report. Annual Report by EAC, Islamabad.

Dahlberg, L., \& Isakson, C. (1996). The implementation of benchmarking: A Swedish perspective. Paris, France: OECD.

Elliot, J. (1976). A general theory of bureaucracy. London, UK: Heinemann.

Expert Advisory Cell Annual Report on Performance of Industrial Enterprises. Annual Publication by EAC, Islamabad.

Gorvine, A. (1966). Administrative reform: Function of political and economic change. In G. S. Birkhead (ed.), Administrative problems in Pakistan. New York, NY: Syracuse University Press.

Government of Pakistan. (1965). The third five-year plan of Pakistan (1965-70). Karachi, Pakistan: The Planning Commission.

Government of Pakistan. (1987). Strategic planning system: Guidelines for preparing strategic plans for individual business units. Boston, MA: Arthur D. Little International, Inc.

Jones, L. (1981). Efficiency of public manufacturing enterprises in Pakistan. Washington, DC: The World Bank.

Jones, L. (1981, November). Towards a performance evaluation methodology for public enterprises: With special reference to Pakistan. Paper presented on" Economic Performance of Public Enterprises in Developing Countries" Islamabad, Pakistan.

Jones, L., \& Mehdi, I. (1985). Position paper on Establishment of Signaling system Islamabad, Pakistan.

Jorion, P. (2007). Value at risk: The new benchmark for managing financial risk. New York, NY: McGraw-Hill.

Mehdi, I. (1984). An anatomy of performance evaluation and incentive system for public enterprises in Pakistan. Pakistan Management Review, Karachi, Pakistan.

Mehdi, I. (1985, July). Setting targets for improving cost efficiencies in public enterprises. Paper presented at a seminar in Karachi, Pakistan.

Mehdi, I. (1988). Pakistan's Experience in the Development and Implementation of the Signaling system for Public Enterprise ICPE, Ljlubljana.

Mehdi, I. (1997, September). Benchmarking for improving efficiency. Paper presented at the commonwealth convention on benchmarking and quality management in Johannesburg, South Africa. 
Mehdi, I. (2014). State corporatization. The News Newspaper.

Nellis, J. (1989). Contract plans and public enterprise performance (Research Working Paper no. 118). Washington, DC: The World Bank.

Shirley, M. (1989). Evaluating the performance of public enterprises in Pakistan. Washington, DC: The World Bank.

Williamson, O. (1975). Markets and hierarchies. New York, NY: The Free Press.

\section{Author Note}

Correspondence concerning this article should be addressed to Istaqbal Mehdi, Al-Aman Holding (Pvt) Ltd, House. 208, Street. 61, E-11/3 Islamabad, Pakistan. Email: Istaqbalmehdi@ hotmail.com

\section{Biographical Note}

Istaqbal Mehdi is a Post Grad with M.A. and M.Phil (Economics) from Government College Lahore, Leeds University, U.K, and Harvard University, U.S.A. He co-authored the world-renowned "Signaling System for Public Enterprises". He synthesized it with corporate planning system, etc., to evolve a programme to reform the public enterprise sector. Following Pakistan's successful experience, he implemented it in the reform programmes of Mexico, The Philippines, etc. Subsequently, he was the CEO of six financial institutions. During his tenure as a Chairman, the rating of Pakistan's Agriculture Bank was raised from ' $\mathrm{D}$ ' to 'AAA'. He was the Chairman of the Assembly of ICPE Slovenia for four years. He has written twenty publications and research papers. 


\section{Appendix}

\section{Experts Advisory Cell \\ Performance Evaluation System \\ 1993-94}

Name of the Unit:

After discussion the following targets are mutually agreed for the year 1993-94

Table 1
Wts
A
$\mathbf{B}$
C
D
$\mathbf{E}$

1. Profitability

2. Physical Production

3. Sales Volume

4. Unit Cost of Production

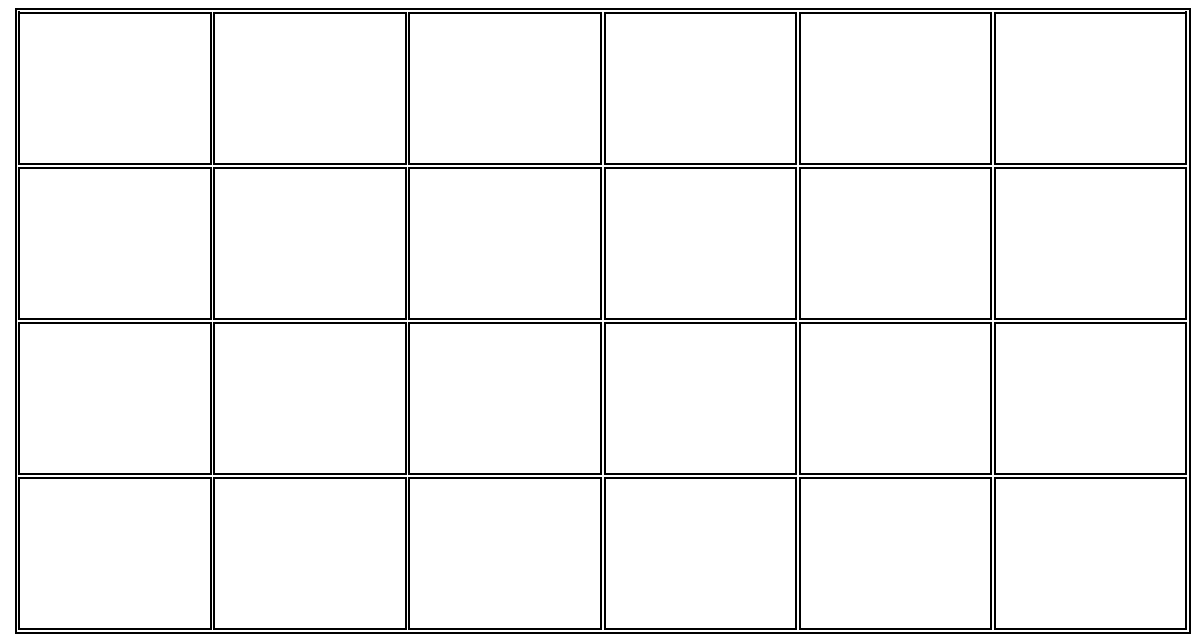

It is agreed that pre-tax profit (Loss)* shall not be less than (more than) Rs. million. In addition, any increase in the targets for following costs ration shall proportionately affect the final grades:

I. Raw Material Consumption

i.

ii

iii

iv

$\mathrm{V}$

II. Energy Consumption

i.

ii

iii
Unit of

$\underline{\text { Measurement }}$

Physical

$\underline{\text { Financial }}$ 
III. Labour Cost

IV. Financial Expenses

CHIEF EXECUTIVE

Profitability * profit before on $\mathrm{x} 100$. Profit before tax reflecting actual performance of the Total bonus

year under review only. Unit shall be entitled for performance bonus in case of profit after tax only.

Note:

1. Target can be adjusted according to the impact of National Budget 1993-94. Revised budget if any, for monitoring shall be submitted by $31^{\text {st }}$ July, 1993, Budget shall be revised keeping in view the basic parameters of the targets.

2. Targets can be reviewed by EAC after the unit's budget is approved by the Board, the Corporation and the Ministry of Production.

3. Above targets are subject to unit's strict adherence to safety measures and required maintenance schedule. 